\title{
U.S. Geological Survey Community for Data Integration: NWIS Web Services Snapshot Tool for ArcGIS
}

U.S. Geological Survey (USGS) data resources are so vast that many scientists are unaware of data holdings that may be directly relevant to their research. Data are also difficult to access and large corporate databases, such as the National Water Information System (NWIS) that houses hydrologic data for the Nation, are challenging to use without considerable expertise and investment of time. The USGS Community for Data Integration (CDI) was established in 2009 to address data and information management issues affecting the proficiency of earth science research.

A CDI workshop convened in 2009 identified common data integration needs of USGS scientists and targeted high value opportunities that might address these needs by leveraging existing projects in USGS science centers, in-kind contributions, and supplemental funding. To implement this strategy, CDI sponsored a software development project in 2010 to facilitate access and use of NWIS data with ArcGIS, a widely used Geographic Information System. The resulting software product, the NWIS Web Services Snapshot Tool for ArcGIS, is presented here.

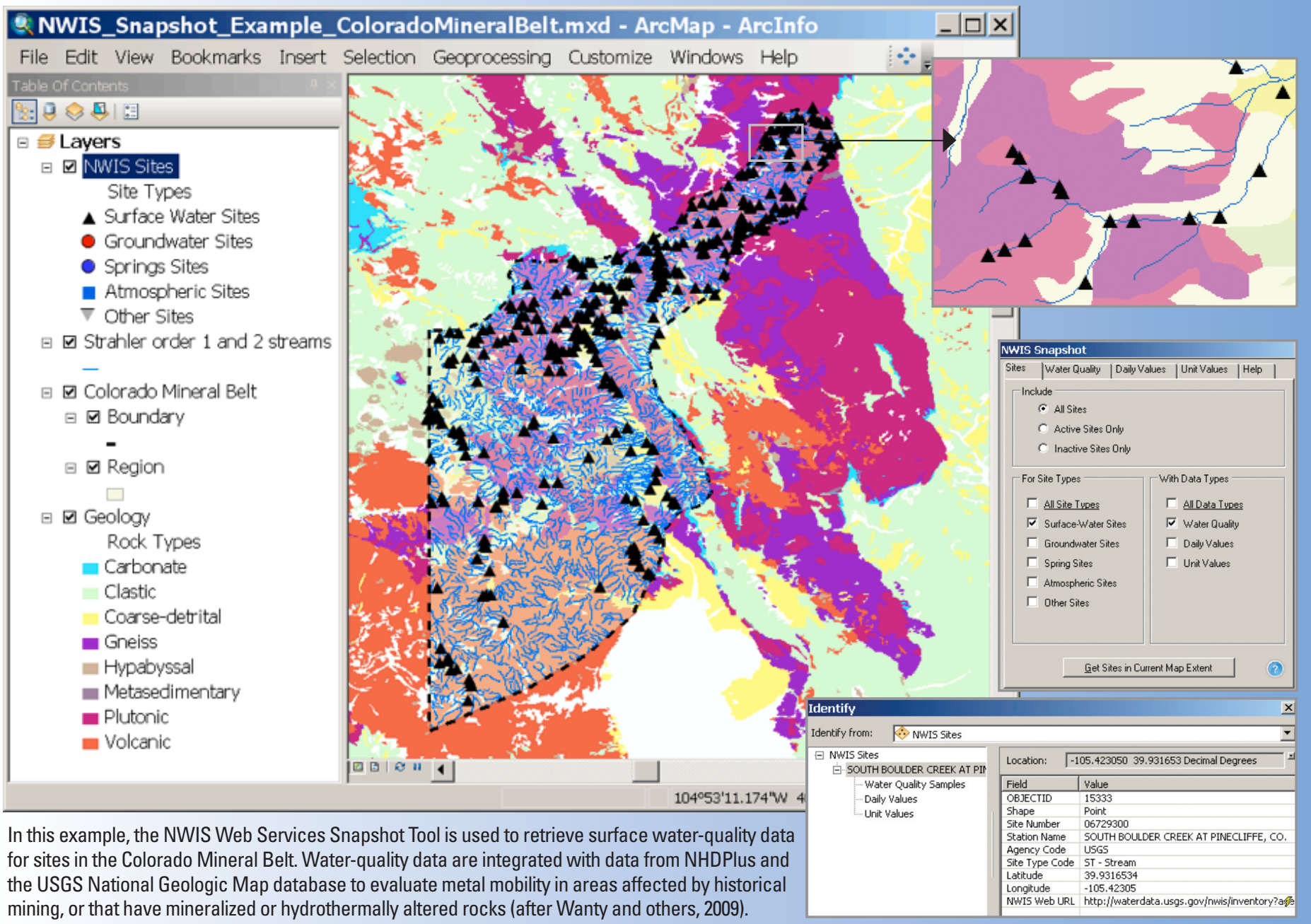

\section{Product}

The NWIS Web Services Snapshot Tool for ArcGIS enables rapid access to NWIS, a database containing hydrologic information for more than 1.5 million surface water, groundwater, and atmospheric monitoring sites throughout the
United States, many with a record of more than 100 years. NWIS data are considered the "gold standard," authoritative source of hydrologic information and are accessed daily by USGS scientists and the public. Access to and management of NWIS data are fundamental to a variety of

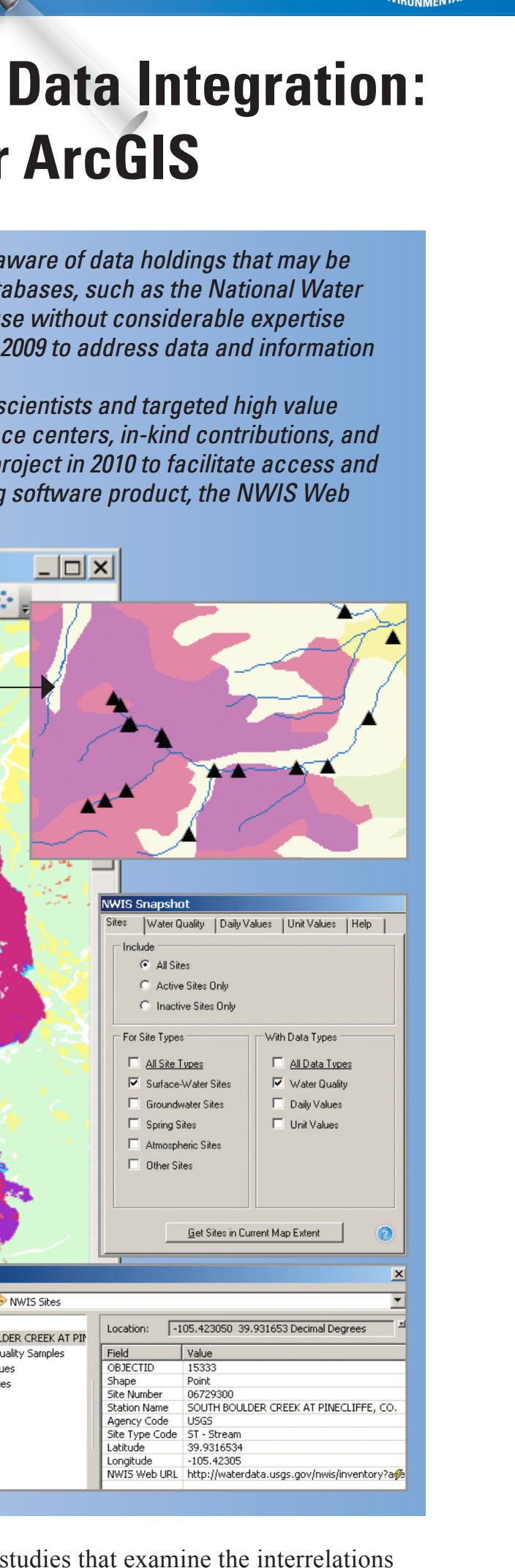

studies that examine the interrelations of the Earth's hydrosphere, biosphere, lithosphere, and atmosphere.

ArcGIS is a software application developed by ESRI and is widely used by and available to all USGS scientists. The Snapshot Tool builds on software 

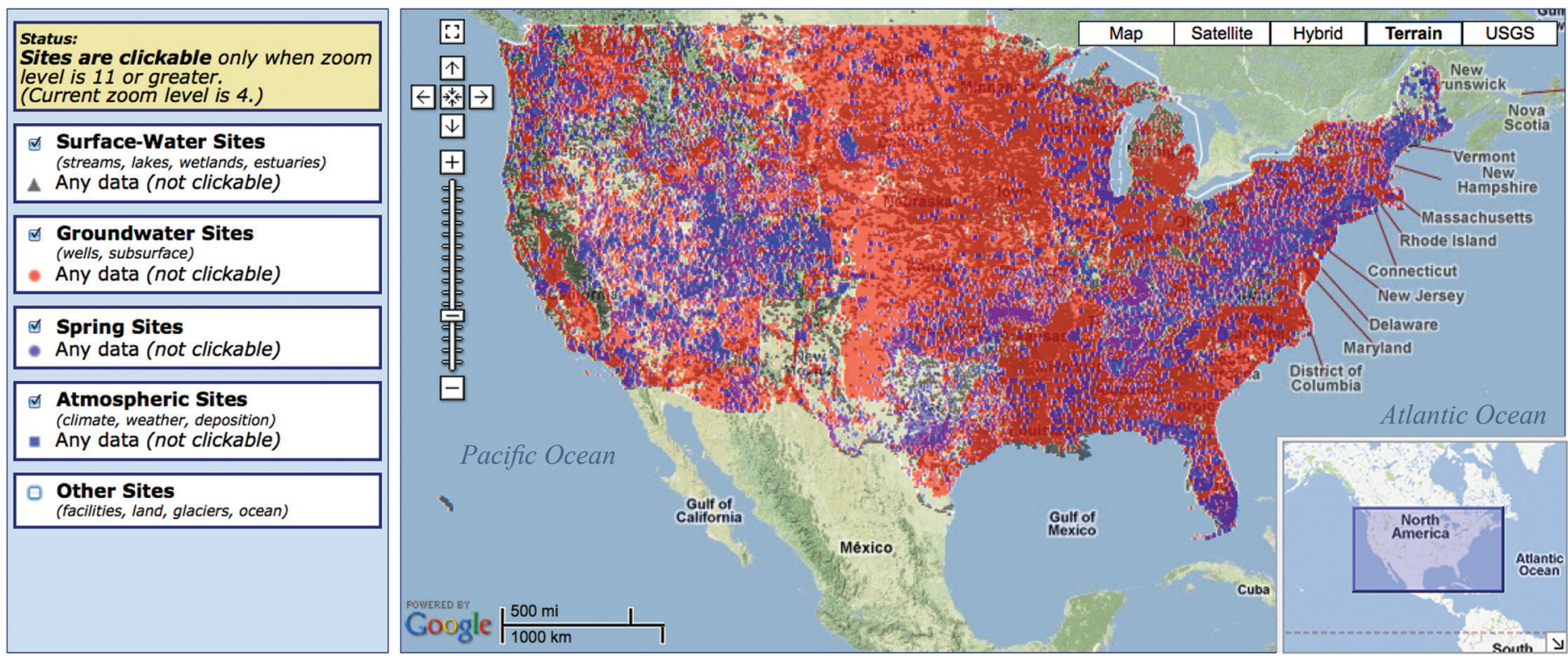

More than 1.5 million NWIS sites blanket the Nation, as shown here on the NWIS Mapper Web site (http://wdr.water.usgs.gov/nwisgmap).

development work of USGS scientists David McCulloch and Brian Reece over the last decade and addresses a critical need to quickly and efficiently access, manage, and use NWIS data within the ArcGIS environment.

The primary scope of the current Snapshot Tool focuses on data retrieval and data management.

The Snapshot Tool allows scientists to query NWIS Web Services databases and download a "snapshot" (subset) of the NWIS data to a local ArcGIS geodatabase. The geodatabase created by Snapshot is structured to allow the scientist to immediately begin working with the data and eliminates the laborious process of reconstructing a workable geodatabase, which is currently the practice.

\section{Data Retrieval}

The Snapshot Tool uses the geospatial capabilities of ArcGIS to retrieve data directly from NWIS Web Services regarding site information, water-quality, instantaneous streamflow, and daily streamflow measurements. Based on user input, the Snapshot Tool sends requests to the NWIS Web Services and uses the returned data to create a geodatabase that reestablishes the relational data structure of NWIS, thus eliminating what once was a laborious and error-prone process. The user can immediately evaluate the spatial display of the data to determine the number, types, and distribution of sites within a study area. In a similar manner, water-quality and streamflow data can be retrieved and assessed to refine subsequent data searches.

\section{Data Management}

The Snapshot Tool creates a geodatabase with predefined relationships between sites and measurements taken at sites so that scientists can make queries, establish relationships with other spatial data, and edit the data without compromising the relational database structure and integrity. The Snapshot Tool translates numerous coded values and field names inherent to NWIS data into plain English so that scientists less familiar with NWIS terms can more readily understand the data. For example, the NWIS field name "parm_unt_tx" is displayed as "Result Unit of Measure" in the ArcGIS geodatabase.

With the NWIS geodatabase established, the scientist can use the functionality of ArcGIS to filter, visualize, and analyze NWIS data. In the ArcGIS environment, common workflow tasks, such as selecting subsets of data using Structured Query Language (SQL), importing data, such as field study results from a spreadsheet, building relationships to other data retrieved using the Snapshot Tool, and exporting data for use in analytical software packages are simplified and thus increase the overall efficiency of research.

\section{Benefits to USGS Science}

The Snapshot Tool allows scientists to explore hydrologic data while saving valuable time. It serves as an educational tool for new or infrequent NWIS users by translating the numerous codes associated with output files of NWIS data and enables efficient data retrieval and management for comprehensive integrated studies. Design and functionality of the Snapshot Tool are driven by the data integration and management needs of USGS scientists to answer questions about climate, the environment, wildlife, and other integrated science topics.

The NWIS Web Services Geodatabase Snapshot Tool and documentation are available at http://txpub.usgs.gov/snapshot.

\section{Reference}

Wanty, R.B., Verplanck, P.L., San Juan, C.A., Church, S.E., Schmidt, T.S., Fey, D.L., DeWitt, E.H., and Klein, T.L., 2009, Geochemistry of surface water in alpine catchments in central Colorado, USAResolving host-rock effects at different spatial scales: Applied Geochemistry, v. 24, no. 4, April 2009, p. 600-610.

Any use of trade, product, or firm names is for descriptive purposes only and does not imply endorsement by the U.S. Government.

Authored by Sally Holl

Design and Layout by Jeanne S. DiLeo

For more information, contact:

NWIS Web Services Snapshot Tool

Director, Texas Water Science Center

U.S. Geological Survey

1505 Ferguson Lane

Austin, TX 78754

512-927-3500

http://txpub.usgs.gov/snapshot

Community for Data Integration

Associate Director for Core Science Systems U.S. Geological Survey

108 National Center, 12201 Sunrise Valley Drive Reston, VA 20192

703-648-5748

http://www.usgs.gov/core_science_systems/ 